\title{
Clinical and prognostic value of preoperative hydronephrosis in upper tract urothelial carcinoma : a systematic review and meta-analysis
}

Yuejun Tian, Yuwen Gong, Yangyang Pang, Zhiping Wang, Mei Hong

Background. Epidemiological studies have reported various results relating preoperative hydronephrosis to upper tract urothelial carcinoma (UTUC). However, the clinical significance and prognostic value of preoperative hydronephrosis in UTUC remains controversial. The aim of this study was to provide a comprehensive meta-analysis of the extent of the possible association between preoperative hydronephrosis and the risk of UTUC. Methods. We searched PubMed, ISI Web of Knowledge, and Embase to identify eligible studies written in English. Summary odds ratios (ORs) or hazard ratios (HRs) and $95 \%$ confidence intervals (Cls) were calculated using fixed-effects or random-effects models. Results. Nineteen relevant studies, which had a total of 5782 UTUC patients enrolled, were selected for statistical analysis. The clinicopathological and prognostic relevance of preoperative hydronephrosis was evaluated in the UTUC patients. The results showed that all tumor stages, lymph node status and tumor location, as well as the risk of cancer specific survival (CSS), overall survival (OS), recurrence-free survival (RFS) and metastasis-free survival (MFS) were significantly different between UTUC patients with elevated preoperative hydronephrosis and those with low preoperative hydronephrosis. High preoperative hydronephrosis indicated a poor prognosis. Additionally, significant correlations between preoperative hydronephrosis and tumor grade (high grade vs. low grade) were observed in UTUC patients; however, no significant difference was observed for tumor grading (G1 vs. $G 2+G 3$ and $G 1+G 2$ vs. $G 3$ ). In contrast, no such correlations were evident for recurrence status or gender in UTUC patients. Conclusions. The results of this meta-analysis suggest that preoperative hydronephrosis is associated with increased risk and poor survival in UTUC patients. The presence of preoperative hydronephrosis plays an important role in the carcinogenesis and prognosis of UTUC. 


\section{Clinical and prognostic value of preoperative \\ 2 hydronephrosis in upper tract urothelial carcinoma: a 3 systematic review and meta-analysis}

4 Yue-jun Tian ${ }^{1}$, Yu-wen Gong ${ }^{1}$, Yang-yang Pang ${ }^{1}$, Zhi-ping Wang ${ }^{1}$ and Mei Hong ${ }^{1,2}$

51 Institute of Urology, Lanzhou University Second Hospital, Key Laboratory of Gansu Province for Urological Diseases, Clinical Center of

6 Gansu Province for Nephro-urology, Lanzhou, Gansu, China

72 Drug Discovery Center, School of chemical Biology and Biotechnology, Peking University Shenzhen Graduate School, Shenzhen, Guangdong,

8 China

9 Corresponding Author: Mei Hong, e-mail: meihonglzu@163.com, meihong@pkusz.edu.cn

10 ABSTRACT

11 Background. Epidemiological studies have reported various results relating preoperative hydronephrosis to upper tract urothelial carcinoma (UTUC). However, the clinical significance and prognostic value of preoperative hydronephrosis in UTUC remains controversial. The aim of this study was to provide a comprehensive metaanalysis of the extent of the possible association between preoperative hydronephrosis and the risk of UTUC.

Methods. We searched PubMed, ISI Web of Knowledge, and Embase to identify eligible studies written in English. Summary odds ratios (ORs) or hazard ratios (HRs) and $95 \%$ confidence intervals (CIs) were calculated using fixedeffects or random-effects models.

Results. Nineteen relevant studies, which had a total of 5782 UTUC patients enrolled, were selected for statistical analysis. The clinicopathological and prognostic relevance of preoperative hydronephrosis was evaluated in the UTUC patients. The results showed that all tumor stages, lymph node status and tumor location, as well as the risk of cancer specific survival (CSS), overall survival (OS), recurrence-free survival (RFS) and metastasis-free survival (MFS) were significantly different between UTUC patients with elevated preoperative hydronephrosis and those with low preoperative hydronephrosis. High preoperative hydronephrosis indicated a poor prognosis. Additionally, significant correlations between preoperative hydronephrosis and tumor grade (high grade vs. low grade) were observed in UTUC patients; however, no significant difference was observed for tumor grading (G1 vs. G2+G3 and G1+G2 vs. G3). In contrast, no such correlations were evident for recurrence status or gender in UTUC patients. 
28

29

30

31

32

33

34

risk and poor survival in UTUC patients. The presence of preoperative hydronephrosis plays an important role in the carcinogenesis and prognosis of UTUC.

\section{INTRODUCTION}

Upper tract urothelial carcinoma (UTUC) accounts for approximately 5 to $10 \%$ of urinary tract carcinomas, including tumors of the urothelium of the renal pelvis and the ureter (Roupret et al., 2015; Siegel et al., 2012). The gold standard management of UTUC is radical nephroureterectomy with bladder-cuff excision for adequate local tumor control and a better survival outcome (Clark et al., 2013; Roupret et al., 2013).

Numerous studies have been conducted to identify the significant prognostic factors of UTUC. The powerful prognostic factors consist of the pathological stage, tumor location, metastasis status, lymphovascular invasion, multi-focality and tumor grade (Kikuchi et al., 2009; Ouzzane et al., 2011; Raman et al., 2010; Roscigno et al., 2008; Roupret et al., 2013). Improved knowledge of the risk factors would help us make better prognostic evaluations for a more effective therapeutic strategy. However, several other putative risk factors have been proposed, and sometimes conflicting results are presented. Preoperative hydronephrosis is also a controversial risk factor. Ito et al. (Ito et al., 2011) confirmed that preoperative hydronephrosis is an independent predictor of poor tumor pathological outcomes in a study of patients with UTUC after nephroureterectomy. In addition, Brien et al. (Brien et al., 2010) reported that preoperative hydronephrosis can identify at-risk UTUC patients. However, controversial results have shown that there is no correlation between preoperative hydronephrosis and the UTUC pathological stage, tumor grade, recurrence, or progression and that preoperative hydronephrosis is not an independent predictor of these outcomes of patients with UTUC (Favaretto et al., 2012; Sakano et al., 2015). With regard to survival, Morizane et al. (Morizane et al., 2013) demonstrated the positive impact of preoperative hydronephrosis using univariate analysis. However, the results of preoperative hydronephrosis as an independent prognostic factor for UTUC using multivariate analyses have been discrepant. Ito et al. (Ito et al., 2011) have also shown that there is no statistical significance between preoperative hydronephrosis and cancer-specific survival (CSS) or metastasis-free survival (MFS) in patients with UTUC. Accordingly, here we perform a systematic review and meta-analysis to clarify whether preoperative hydronephrosis is an independent risk factor influencing the progression and survival of UTUC.

\section{MATERIALS AND METHODS}

\section{Literature research}


55 This meta-analysis followed the Preferred Reporting Items for Systematic Reviews and Meta-analyses (PRISMA) statement (Moher et al., 2010). A systematic literature search using PubMed, ISI Web of Knowledge, and Embase was conducted to retrieve clinical studies up to March 1, 2016. The search terms used included the following: "ureteral neoplasms", "urothelium", “ureter", "renal pelvis", “upper tract urothelial", "hydronephrosis", "preoperative hydronephrosis", "prognosis or prognostic or outcome", and relevant variants of these search terms. The following criteria were used to determine study eligibility: (1) must concern the connection between preoperative hydronephrosis and clinicopathological characteristics and the prognosis of UTUC; (2) UTUC patients must have been diagnosed using the standard histopathological examination criteria; and (3) must provide information about the preoperative hydronephrosis. The exclusion criteria for the study were: (a) studies lacking original data; (b) not written in English; and (c) reviews, meta-analyses, case reports, abstracts, or meeting records. For overlapping articles, we included the most informative and latest article.

\section{Data Extraction and Quality Assessment}

All data were independently reviewed by 2 researchers (YWG and YYP) and were cross-checked. Additionally, any disagreement or uncertainty was resolved using group discussion. The quality of the selected articles was assessed according to the Newcastle-Ottawa scale (NOS) criteria (Stang, 2010). For quality, scores ranged from 0 (lowest) to 9 (greatest); studies with scores of 5 or more were graded as good quality. The data extracted from these citations included the name of the first author, publication year, country, number of patients, recruitment period, sex ratio, age, cut-off, prognostic outcomes, pathological stage, lymph node dissection, tumor grade, and tumor location. The data were extracted from the original articles. Situations lacking exact data were resolved in a number of ways: multivariate outcomes were used before univariate outcomes when both were presented, but if no multivariate results were presented, univariate outcomes were used instead.

\section{Statistical analysis}

Odds ratios (ORs) and 95\% CIs were used to estimate the relationships between preoperative hydronephrosis and clinicopathological parameters, including pathologic tumor stage, tumor grade, lymph node status, tumor location, recurrence status, and gender. HRs and 95\% CIs were used to evaluate the relationships between preoperative hydronephrosis and cancer-specific survival (CSS), overall survival (OS), recurrence-free survival (RFS), or metastasis-free survival (MFS). A p-value of $<0.05$ was considered statistically significant. The statistical 
82 significance of the pooled ORs and HRs was evaluated using a Z-test. Heterogeneity among studies was evaluated

83

84

using the Cochran Q-statistic and the $\mathrm{I}^{2}$ test (Zintzaras \& Ioannidis, 2005). A random effects model was used when significant heterogeneity existed among studies $\left(\mathrm{P}<0.05\right.$ or $\left.\mathrm{I}^{2}>50 \%\right)$; otherwise, a fixed-effects model was used. Funnel plots and Begg's test were used to evaluate the potential publication bias (Peters et al., 2006). All statistical calculations were performed using Review Manager 5.3 (The Cochrane Collaboration, Copenhagen) and STATA version 14.0 (Stata Corp, College Station, TX).

\section{RESULTS}

\section{Eligible studies and quality assessment}

Initially, our search strategy identified 357 articles. A total of 19 studies published between 2007 and 2016 were included in the final meta-analysis (Bozzini et al., 2013; Chapman et al., 2009; Chen et al., 2013; Cho et al., 2007; Chung et al., 2014; Colin et al., 2014; Fradet et al., 2014; Hwang et al., 2013; Liang et al., 2016; Luo et al., 2013; Messer et al., 2013; Ng et al., 2011; Sakano et al., 2013; Xing et al., 2016; Yeh et al., 2015; Zhang et al., 2016; Zhang et al., 2013; Zhang et al., 2015; Zou et al., 2014)(Fig. 1). Thirteen studies provided original information of the relationships between preoperative hydronephrosis and the clinicopathological parameters of UTUC patients directly (Bozzini et al., 2013; Chapman et al., 2009; Chen et al., 2013; Cho et al., 2007; Chung et al., 2014; Fradet et al., 2014; Hwang et al., 2013; Liang et al., 2016; Messer et al., 2013; Ng et al., 2011; Yeh et al., 2015; Zhang et al., 2013; Zhang et al., 2015). Fourteen articles assessed the prognostic value of preoperative hydronephrosis (CSS/OS/RFS/MFS) of UTUC patients using the Kaplan-Meier method (Bozzini et al., 2013; Chapman et al., 2009; Chung et al., 2014; Colin et al., 2014; Hwang et al., 2013; Liang et al., 2016; Luo et al., 2013; Ng et al., 2011; Sakano et al., 2013; Xing et al., 2016; Yeh et al., 2015; Zhang et al., 2016; Zhang et al., 2013; Zhang et al., 2015). The main characteristics of the 19 studies included in our meta-analysis are shown in Table 1. Other characteristics, such as the pathological results and the prognostic features, are summarized in S Table 1, S Table 2, and S Table 3. A total of 5782 patients were included in this meta-analysis, and they were from 7 countries (Korea, USA, Japan, France, China, Canada, Taiwan). The median follow-up period of the studies ranged from 1 month to 233 months. The age of the patients ranged from 20 to 95 years, and the overall proportion of males was $51.74 \%$.

Present/high preoperative hydronephrosis was defined using radiographic reports. Differences in the cut-off value of present/high preoperative hydronephrosis were observed among the studies. Preoperative hydronephrosis that was 
109

110

111

112

113

114

115

116

117

118

119

120

121

122

123

124

125

126

127

128

129

130

131

132

133

134

135

present or a high grade was considered to be positive, and absent or a low grade was considered to be negative.

Fourteen articles evaluated the prognostic value of preoperative hydronephrosis (CSS/OS/RFS/MFS) in UTUC patients. Of the 14 studies, 12 provided HR and $95 \%$ CI values directly; of the other 2 studies, one paper provided the relative risk (RR), and the other article provided OR values, which we used to estimate HR. Of the 14 studies, a significant association between preoperative hydronephrosis and poor CSS, OS, RFS or MFS was demonstrated in six (Chung et al., 2014; Liang et al., 2016; Ng et al., 2011; Yeh et al., 2015; Zhang et al., 2013; Zhang et al., 2015), four (Chapman et al., 2009; Liang et al., 2016; Yeh et al., 2015; Zhang et al., 2015), three (Chung et al., 2014; Hwang et al., 2013; Luo et al., 2013) or one (Ng et al., 2011) studies, respectively. Of the literature, the six (Bozzini et al., 2013; Sakano et al., 2013; Xing et al., 2016; Yeh et al., 2015; Zhang et al., 2016; Zou et al., 2014), two (Bozzini et al., 2013; Yeh et al., 2015), four (Chung et al., 2014; Liang et al., 2016; Luo et al., 2013; Ng et al., 2011) or three (Bozzini et al., 2013; Colin et al., 2014; Luo et al., 2013) studies linking preoperative hydronephrosis with poor CSS, OS, RFS or MFS, respectively, lacked statistical significance.

\section{Survival Outcomes}

Of the 12 studies investigating the association between preoperative hydronephrosis and CSS, the pooled HR and $95 \%$ CI for UTUC patients was $1.69(95 \%$ CI $1.23-2.33, \mathrm{P}=0.001, \mathrm{n}=3063)$ with heterogeneity $\left(\mathrm{I}^{2}=70 \%, \mathrm{P}=0.0001\right.$; Table 2 and Fig. 2A). The pooled HR and $95 \%$ CI for OS provided in six studies was 1.62 (95\% CI 1.35-1.94, P < $0.00001)$ with heterogeneity $\left(\mathrm{I}^{2}=17 \%, \mathrm{P}=0.30\right.$; Table 2 and Fig. $\left.2 \mathrm{~B}\right)$.

The results also demonstrated significant associations between presence of preoperative hydronephrosis and shorter RFS and MFS, respectively; the combined HRs were 1.95, $95 \%$ CI 1.26-3.04, P = 0.003 and $1.55,95 \%$ CI $1.04-$ 2.33, $\mathrm{P}=0.03$, respectively (Table 2, S Fig. 3A, and S Fig. 3B).

\section{Relationships between preoperative hydronephrosis and clinicopathological parameters}

In this meta-analysis, clinicopathological features such as tumor stage, tumor grade, lymph node status, tumor location, recurrence status, and gender, as impacted by the presence of preoperative hydronephrosis, were compared using the 13 studies. The results of the meta-analysis showed significant associations between presence of preoperative hydronephrosis and higher tumor stage (T2-4), positive lymph node metastatic status or ureter tumor location, respectively; the combined ORs and $95 \%$ CIs were as follows: OR 3.12, $95 \%$ CI 1.85-5.27, P $<0.0001$; OR 1.60, $95 \%$ CI 1.13-2.26, P = 0.009; OR 3.75, $95 \%$ CI 2.44-5.77, P < 0.00001 (Table 3, S Fig. 1A, S Fig. 2A, 
136

137

and S Fig. 2B). Moreover, significant associations between preoperative hydronephrosis and tumor stage (high grade vs. low grade) were observed only in UTUC patients. The OR and 95 \% CI was as follows: OR 1.66, $95 \%$ CI $1.20-$ 2.29, $\mathrm{P}=0.002$ (Table 3 and S Fig. 1B). There was no significant association between preoperative hydronephrosis and tumor grade (G3 vs. G1+G2 and G2+G3 vs. G1, respectively); the combined ORs and $95 \%$ CIs were OR 1.42 , $95 \%$ CI $0.75-2.69, \mathrm{P}=0.28$ and OR 0.94, $95 \%$ CI 0.49-1.79, P = 0.85 (Table 3, S Fig. 1C, and S Fig. 1D).

Finally, there was no significant association between preoperative hydronephrosis and recurrence status (bladder recurrence vs. no bladder recurrence) or gender (male vs. female), respectively; the combined ORs and $95 \%$ CIs were OR 1.28, $95 \%$ CI 0.92-1.77, $\mathrm{P}=0.14$ and OR 1.01, $95 \%$ CI 0.83-1.22, P=0.927 (Table 3, S Fig. 2C, and S Fig. 2D).

\section{Publication Bias}

Publication bias was assessed using Begg's test and Egger's test for asymmetry only for cancer-specific survival (CSS) of UTUC (Fig. 3A and Fig. 3B). No evidence of asymmetry was found using our funnel plot. Begg's test (P= 0.244) and Egger's test $(\mathrm{P}=0.093)$ suggested that our analyses were stable.

\section{DISCUSSION}

Increasing evidence has shown that preoperative hydronephrosis can be present in bladder tumors and UTUC. The presence of preoperative hydronephrosis in patients with bladder cancer is a predictive factor for poor pathological outcome and a poor prognosis (Bartsch et al., 2007; Divrik et al., 2007). In addition, Hurel et al. (Hurel et al., 2015) reported that hydronephrosis correlated with ureteral location, renal failure, urinary infection, positive cytology, the absence of hematuria and a fortuitous UTUC diagnosis. However, despite this finding, the relationship of preoperative hydronephrosis with UTUC outcome remains unclear, and the roles of preoperative hydronephrosis in UTUC and its clinical significance have not yet been thoroughly investigated.

The results of the analysis of the pooled data of this study showed the following: (a) preoperative hydronephrosis was associated with tumor stage, lymph node metastatic status, and tumor location in UTUC patients; (b) preoperative hydronephrosis was not strongly associated with tumor grade, gender or recurrence status in UTUC patients; (c) UTUC patients with preoperative hydronephrosis had a lower survival rate than those without preoperative hydronephrosis; (d) ureteral tumors were associated with a poorer prognosis than renal pelvic tumors (Park et al., 2009; Park et al., 2004; Wu et al., 2014). A hypothesis to at least partially explain this result may be 
163

164

165

166

167

168

169

170

171

172

173

174

175

176

177

178

179

180

181

182

183

184

185

186

187

188

189

that ureteral tumors are more likely to have hydronephrosis.

The biological mechanism of preoperative hydronephrosis explains its prognostic significance in UTUC. The presence of preoperative hydronephrosis is associated with poor renal function (Hoshino et al., 2012; Rodriguez Faba et al., 2014). Because long-term obstruction of the upper urinary tract would lead to renal function damage, it is not difficult to understand the relationship between hydronephrosis and renal function. $\mathrm{Ng}$ et al. (Ng et al., 2011) pointed out that preoperative hydronephrosis is common in UTUC patients and may be due to one of several factors including intramural invasion, luminal obstruction and extrinsic compression. Furthermore, some researchers speculated that hydronephrosis may induce outward expansion and longitudinal thinning of the already narrow renal pelvis or ureter wall, which may promote the seeding of cancer cells to regional or distant organs. Hydronephrosis may also induce increased outward centrifugal pressure causing counter flow in lymphatics and vasculature, which may lead to increased cancer seeding (Chung et al., 2014). The presence of preoperative hydronephrosis is more common in UTUC than in bladder cancer, which may be attributed to a urinary tract obstruction of a small mass being more likely to occur in the ureter (Zhang et al., 2015). In addition, Stravodimos et al. (Stravodimos et al., 2009), using immunohistochemical and morphological studies, found that hydronephrosis could lead to ischemic changes, along with increased expression of hypoxia-inducible factor-1a (HIF-1a), in UTUC. HIF-1a is thought to be associated with enhanced tumor cell growth and neovascularization, which is also correlated with aggressive cancer behavior (Chai et al., 2008; Deniz et al., 2010).

To our knowledge, the present meta-analysis is the first study to systematically evaluate the associations of preoperative hydronephrosis and clinicopathological features and prognostic value in UTUC. The presence of preoperative hydronephrosis predicted poorer pathological outcome and was a significant risk factor affecting survival.

Several limitations of this study need to be acknowledged. Regarding the studies included, first is the limitations inherent to the biases related to the general prevalence of retrospective studies because no prospective studies were established. Moreover, other clinical factors, such as race, age, sample size, different surgical approaches or different chemotherapies, of each study might lead to bias. Non-English studies, unpublished studies, and studies that did not provide sufficient data of the calculated HRs did not contribute to assessing the predictive value of preoperative hydronephrosis for survival. These approaches may have produced errors because of possible 
190

191

192

193

194

195

196

197

198

199

200

201

202

203

204

205

206

207

208

209

210

211

212

213

214

215

216

217

218

219

220

221

222

inaccurate reading. Finally, although we included 19 studies comprising 5782 cases in this meta-analysis, some studies were categorized for subgroup analysis, and several survival subgroup analyses lacked data. Therefore, these results need to be further confirmed using an adequately designed prospective study to provide a better conclusion with respect to the relationship between preoperative hydronephrosis and the outcome of patients with UTUC.

\section{CONCLUSIONS}

Although larger well-designed studies including more ethnic groups, as well as larger population studies, are required, our meta-analysis has demonstrated that preoperative hydronephrosis was associated with prognosisrelevant factors, including tumor stage, lymph node status, and tumor location, which led to a poor CSS, OS, RFS and MFS rate in UTUC. The evaluation of preoperative hydronephrosis may therefore be informative for decisions concerning surgical strategy, and the preoperative presence of hydronephrosis should raise the possibility of employing an aggressive treatment strategy.

Figure 1 Flow chart showing the study selection process.

Figure 2 (A) The hazard ratio (HR) of preoperative hydronephrosis associated with CSS in UTUC patients; (B) The hazard ratio (HR) of preoperative hydronephrosis associated with OS in UTUC patients.

Figure 3 Funnel plots were used to evaluate publication bias on CSS. Begg's test and Egger's test were not significant intending no significant bias was observed on CSS (A and B).

\section{Table 1 Summary of the characteristics of enrolled studies.}

Table 2 HR values of CSS, OS, RFS and MFS of UTUC.

Table 3 OR values for UTUC subgroups according to clinical characteristics.

\section{Supporting Information}

S Figure 1 (A) The odds ratio (OR) of preoperative hydronephrosis associated with tumor stage in UTUC patients (Ta/1 vs T2-4); (B) The odds ratio (OR) of preoperative hydronephrosis associated with tumor grade in UTUC patients (High grade vs. Low grade); (C) The odds ratio (OR) of preoperative hydronephrosis associated with tumor grade in UTUC patients (G3 vs. G1+G2); (D) The odds ratio (OR) of preoperative hydronephrosis associated with tumor grade in UTUC patients (G2+G3 vs. G1). 
223

224

225

226

227

228

229

230

231

232

233

234

235

236

237

238

239

240

241

242

243

244

245

246

247

248

249

250

251

252

253

254

255

256

257

258

259

260

261

262

263

S Figure 2 (A) The odds ratio (OR) of preoperative hydronephrosis associated with lymph node status in UTUC patients (Lymph node metastasis vs. No lymph node metastasis); (B) The odds ratio (OR) of preoperative hydronephrosis associated with tumor location in UTUC patients (Renal pelvis vs. Ureter); (C) The odds ratio (OR) of preoperative hydronephrosis associated with recurrence status in UTUC patients (Recurrence vs. No recurrence); (D) The odds ratio (OR) of preoperative hydronephrosis associated with gender in UTUC patients (Male vs. Female).

S Figure 3 (A) The hazard ratio (HR) of associated with RFS in UTUC patients; (B) The hazard ratio (HR) of associated with MFS in UTUC patients.

S Table 1 Estimation of the hazard ratio. (DOCX)

S Table 2 Preoperative hydronephrosis according to pathological features. (DOCX)

S Table 3 Preoperative hydronephrosis according to tumor features. (DOCX)

S Table 4 PRISMA 2009 checklist in current meta-analysis. (DOCX)

S Table 5 The copy of Figure 3. (XLSX)

\section{REFERENCES}

Bartsch GC, Kuefer R, Gschwend JE, de Petriconi R, Hautmann RE, and Volkmer BG. 2007. Hydronephrosis as a prognostic marker in bladder cancer in a cystectomy-only series. Eur Urol 51:690-697; discussion 697-698 DOI 10.1016/j.eururo.2006.07.009.

Bozzini G, Nison L, Colin P, Ouzzane A, Yates DR, Audenet F, Pignot G, Arvin-Berod A, Merigot O, Guy L, Irani J, Saint F, Gardic S, Gres P, Rozet F, Neuzillet Y, Ruffion A, and Roupret M. 2013. Influence of preoperative hydronephrosis on the outcome of urothelial carcinoma of the upper urinary tract after nephroureterectomy: the results from a multi-institutional French cohort. World J Urol 31:83-91 DOI 10.1007/s00345-012-0964-4.

Brien JC, Shariat SF, Herman MP, Ng CK, Scherr DS, Scoll B, Uzzo RG, Wille M, Eggener SE, Terrell JD, Lucas SM, Lotan Y, Boorjian SA, and Raman JD. 2010. Preoperative hydronephrosis, ureteroscopic biopsy grade and urinary cytology can improve prediction of advanced upper tract urothelial carcinoma. $J$ Urol 184:69-73 DOI 10.1016/j.juro.2010.03.030.

Chai CY, Chen WT, Hung WC, Kang WY, Huang YC, Su YC, and Yang CH. 2008. Hypoxia-inducible factor1alpha expression correlates with focal macrophage infiltration, angiogenesis and unfavourable prognosis in urothelial carcinoma. J Clin Pathol 61:658-664 DOI 10.1136/jcp.2007.050666.

Chapman DM, Pohar KS, Gong MC, and Bahnson RR. 2009. Preoperative hydronephrosis as an indicator of survival after radical cystectomy. Urol Oncol 27:491-495 DOI 10.1016/j.urolonc.2008.06.001.

Chen XP, Xiong GY, Li XS, Matin SF, Garcia M, Fang D, Wang TY, Yu W, Gong K, Song Y, He ZS, He Q, and Zhou LQ. 2013. Predictive factors for worse pathological outcomes of upper tract urothelial carcinoma: experience from a nationwide high-volume centre in China. BJU Int 112:917-924 DOI 


\subsection{1/bju.12238.}

Cho KS, Hong SJ, Cho NH, and Choi YD. 2007. Grade of hydronephrosis and tumor diameter as preoperative prognostic factors in ureteral transitional cell carcinoma. Urology 70:662-666 DOI 10.1016/j.urology.2007.06.1106.

Chung PH, Krabbe LM, Darwish OM, Westerman ME, Bagrodia A, Gayed BA, Haddad AQ, Kapur P, Sagalowsky AI, Lotan Y, and Margulis V. 2014. Degree of hydronephrosis predicts adverse pathological features and worse oncologic outcomes in patients with high-grade urothelial carcinoma of the upper urinary tract. Urol Oncol 32:981-988 DOI 10.1016/j.urolonc.2014.02.018.

Clark PE, Agarwal N, Biagioli MC, Eisenberger MA, Greenberg RE, Herr HW, Inman BA, Kuban DA, Kuzel TM, Lele SM, Michalski J, Pagliaro LC, Pal SK, Patterson A, Plimack ER, Pohar KS, Porter MP, Richie JP, Sexton WJ, Shipley WU, Small EJ, Spiess PE, Trump DL, Wile G, Wilson TG, Dwyer M, Ho M, and National Comprehensive Cancer N. 2013. Bladder cancer. J Natl Compr Canc Netw 11:446-475.

Colin P, Ghoneim TP, Nison L, Seisen T, Lechevallier E, Cathelineau X, Ouzzane A, Zerbib M, Long JA, Ruffion A, Crouzet S, Cussenot O, Audouin M, Irani J, Gardic S, Gres P, Audenet F, Roumiguie M, Valeri A, and Roupret M. 2014. Risk stratification of metastatic recurrence in invasive upper urinary tract carcinoma after radical nephroureterectomy without lymphadenectomy. World J Urol 32:507-512 DOI 10.1007/s00345-013-1116-1.

Deniz H, Karakok M, Yagci F, and Guldur ME. 2010. Evaluation of relationship between HIF-1alpha immunoreactivity and stage, grade, angiogenic profile and proliferative index in bladder urothelial carcinomas. Int Urol Nephrol 42:103-107 DOI 10.1007/s11255-009-9590-5.

Divrik RT, Sahin A, Altok M, Unlu N, and Zorlu F. 2007. The frequency of hydronephrosis at initial diagnosis and its effect on recurrence and progression in patients with superficial bladder cancer. $J$ Urol 178:802-806; discussion 806 DOI 10.1016/j.juro.2007.05.054.

Favaretto RL, Shariat SF, Savage C, Godoy G, Chade DC, Kaag M, Bochner BH, Coleman J, and Dalbagni G. 2012. Combining imaging and ureteroscopy variables in a preoperative multivariable model for prediction of muscle-invasive and non-organ confined disease in patients with upper tract urothelial carcinoma. BJU Int 109:77-82 DOI 10.1111/j.1464-410X.2011.10288.x.

Fradet V, Mauermann J, Kassouf W, Rendon R, Jacobsen N, Fairey A, Izawa J, Kapoor A, Black P, Tanguay S, Chin J, So A, Lattouf JB, Bell D, Saad F, Sheyegan B, Drachenberg D, Cagiannos I, and Lacombe L. 2014. Risk factors for bladder cancer recurrence after nephroureterectomy for upper tract urothelial tumors: results from the Canadian Upper Tract Collaboration. Urol Oncol 32:839-845 DOI 10.1016/j.urolonc.2014.04.006.

Hoshino K, Kikuchi E, Tanaka N, Akita H, Ito Y, Miyajima A, Jinzaki M, and Oya M. 2012. Preoperative hydronephrosis: independent predictor for changes in renal function following nephroureterectomy. Jpn J Clin Oncol 42:202-207 DOI 10.1093/jjco/hyr199.

Hurel S, Roupret M, Seisen T, Comperat E, Phe V, Droupy S, Audenet F, Pignot G, Cathelineau X, Guy L, Cussenot O, Ouzzane A, Bozzini G, Nison L, Ruffion A, and Colin P. 2015. Influence of preoperative factors on the oncologic outcome for upper urinary tract urothelial carcinoma after radical nephroureterectomy. World J Urol 33:335-341 DOI 10.1007/s00345-014-1311-8.

Hwang I, Jung SI, Nam DH, Hwang EC, Kang TW, Kwon DD, and Ryu SB. 2013. Preoperative hydronephrosis 
and diabetes mellitus predict poor prognosis in upper urinary tract urothelial carcinoma. Can Urol Assoc $J$ 7:E215-220 DOI 10.5489/cuaj.11236.

Ito Y, Kikuchi E, Tanaka N, Miyajima A, Mikami S, Jinzaki M, and Oya M. 2011. Preoperative hydronephrosis grade independently predicts worse pathological outcomes in patients undergoing nephroureterectomy for upper tract urothelial carcinoma. J Urol 185:1621-1626 DOI 10.1016/j.juro.2010.12.035.

Kikuchi E, Margulis V, Karakiewicz PI, Roscigno M, Mikami S, Lotan Y, Remzi M, Bolenz C, Langner C, Weizer A, Montorsi F, Bensalah K, Koppie TM, Fernandez MI, Raman JD, Kassouf W, Wood CG, Suardi N, Oya M, and Shariat SF. 2009. Lymphovascular invasion predicts clinical outcomes in patients with node-negative upper tract urothelial carcinoma. J Clin Oncol 27:612-618 DOI 10.1200/JCO.2008.17.2361.

Liang C, Chi R, Huang L, Wang J, Liu H, Xu D, Qian S, Qian X, and Qi J. 2016. Upper Tract Urothelial Carcinomas Accompanied by Previous or Synchronous Nonmuscle-Invasive Bladder Cancer and Preoperative Hydronephrosis Might Have Worse Oncologic Outcomes After Radical Nephroureterectomy. Clin Genitourin Cancer DOI 10.1016/j.clgc.2016.02.008.

Luo HL, Kang CH, Chen YT, Chuang YC, Lee WC, Cheng YT, and Chiang PH. 2013. Severity of hydronephrosis correlates with tumour invasiveness and urinary bladder recurrence of ureteric cancer. BJU Int 112:489-494 DOI 10.1111/bju.12157.

Messer JC, Terrell JD, Herman MP, Ng CK, Scherr DS, Scoll B, Boorjian SA, Uzzo RG, Wille M, Eggener SE, Lucas SM, Lotan Y, Shariat SF, and Raman JD. 2013. Multi-institutional validation of the ability of preoperative hydronephrosis to predict advanced pathologic tumor stage in upper-tract urothelial carcinoma. Urol Oncol 31:904-908 DOI 10.1016/j.urolonc.2011.07.011.

Moher D, Liberati A, Tetzlaff J, Altman DG, and Group P. 2010. Preferred reporting items for systematic reviews and meta-analyses: the PRISMA statement. Int J Surg 8:336-341 DOI 10.1016/j.ijsu.2010.02.007.

Morizane S, Iwamoto H, Masago T, Yao A, Isoyama T, Sejima T, and Takenaka A. 2013. Preoperative prognostic factors after radical nephroureterectomy in patients with upper urinary tract urothelial carcinoma. Int Urol Nephrol 45:99-106 DOI 10.1007/s11255-012-0347-1.

Ng CK, Shariat SF, Lucas SM, Bagrodia A, Lotan Y, Scherr DS, and Raman JD. 2011. Does the presence of hydronephrosis on preoperative axial CT imaging predict worse outcomes for patients undergoing nephroureterectomy for upper-tract urothelial carcinoma? Urol Oncol 29:27-32 DOI 10.1016/j.urolonc.2008.10.023.

Ouzzane A, Colin P, Xylinas E, Pignot G, Ariane MM, Saint F, Hoarau N, Adam E, Azemar MD, Bensadoun H, Cormier L, Cussenot O, Houlgatte A, Karsenty G, Bruyere F, Maurin C, Nouhaud FX, Phe V, Polguer T, Roumiguie M, Ruffion A, Roupret M, and French Collaborative National Database on UU. 2011. Ureteral and multifocal tumours have worse prognosis than renal pelvic tumours in urothelial carcinoma of the upper urinary tract treated by nephroureterectomy. Eur Urol 60:1258-1265 DOI 10.1016/j.eururo.2011.05.049.

Park J, Ha SH, Min GE, Song C, Hong B, Hong JH, Kim CS, and Ahn H. 2009. The protective role of renal parenchyma as a barrier to local tumor spread of upper tract transitional cell carcinoma and its impact on patient survival. J Urol 182:894-899 DOI 10.1016/j.juro.2009.05.040.

Park S, Hong B, Kim CS, and Ahn H. 2004. The impact of tumor location on prognosis of transitional cell carcinoma of the upper urinary tract. $J$ Urol 171:621-625 DOI 10.1097/01.ju.0000107767.56680.f7. 
Peters JL, Sutton AJ, Jones DR, Abrams KR, and Rushton L. 2006. Comparison of two methods to detect publication bias in meta-analysis. JAMA 295:676-680 DOI 10.1001/jama.295.6.676.

Raman JD, Ng CK, Scherr DS, Margulis V, Lotan Y, Bensalah K, Patard JJ, Kikuchi E, Montorsi F, Zigeuner R, Weizer A, Bolenz C, Koppie TM, Isbarn H, Jeldres C, Kabbani W, Remzi M, Waldert M, Wood CG, Roscigno M, Oya M, Langner C, Wolf JS, Strobel P, Fernandez M, Karakiewcz P, and Shariat SF. 2010. Impact of tumor location on prognosis for patients with upper tract urothelial carcinoma managed by radical nephroureterectomy. Eur Urol 57:1072-1079 DOI 10.1016/j.eururo.2009.07.002.

Rodriguez Faba O, Palou J, Breda A, Maroto P, Fernandez Gomez JM, Wong A, and Villavicencio H. 2014. Predictive factors for impaired renal function following nephroureterectomy in upper urinary tract urothelial cell carcinoma. Urol Int 92:169-173 DOI 10.1159/000353652.

Roscigno M, Cozzarini C, Bertini R, Scattoni V, Freschi M, Da Pozzo LF, Briganti A, Gallina A, Capitanio U, Colombo R, Giorgio G, Montorsi F, and Rigatti P. 2008. Prognostic value of lymph node dissection in patients with muscle-invasive transitional cell carcinoma of the upper urinary tract. Eur Urol 53:794-802 DOI 10.1016/j.eururo.2008.01.008.

Roupret M, Babjuk M, Comperat E, Zigeuner R, Sylvester R, Burger M, Cowan N, Bohle A, Van Rhijn BW, Kaasinen E, Palou J, Shariat SF, and European Association of U. 2013. European guidelines on upper tract urothelial carcinomas: 2013 update. Eur Urol 63:1059-1071 DOI 10.1016/j.eururo.2013.03.032.

Roupret M, Babjuk M, Comperat E, Zigeuner R, Sylvester RJ, Burger M, Cowan NC, Bohle A, Van Rhijn BW, Kaasinen E, Palou J, and Shariat SF. 2015. European Association of Urology Guidelines on Upper Urinary Tract Urothelial Cell Carcinoma: 2015 Update. Eur Urol 68:868-879 DOI 10.1016/j.eururo.2015.06.044.

Sakano S, Inamoto T, Inoue R, Matsumoto H, Nagao K, Yamamoto Y, Azuma H, and Matsuyama H. 2015. Positive voided urine cytology predicts worse pathological findings of nephroureterectomy specimens in patients with upper tract urothelial carcinoma: does selective ureteral cytology have an additional efficacy? Jpn J Clin Oncol 45:968-972 DOI 10.1093/jjco/hyv114.

Sakano S, Matsuyama H, Kamiryo Y, Hayashida S, Yamamoto N, Kaneda Y, Nasu T, Hashimoto O, Joko K, Baba Y, Shimabukuro T, Suga A, Yamamoto M, Aoki A, Takai K, Yoshihiro S, Matsumura M, and Yamaguchi Uro-Oncology G. 2013. Risk group stratification based on preoperative factors to predict survival after nephroureterectomy in patients with upper urinary tract urothelial carcinoma. Ann Surg Oncol 20:4389-4396 DOI 10.1245/s10434-013-3259-0.

Siegel R, Naishadham D, and Jemal A. 2012. Cancer statistics, 2012. CA Cancer J Clin 62:10-29 DOI 10.3322/caac. 20138.

Stang A. 2010. Critical evaluation of the Newcastle-Ottawa scale for the assessment of the quality of nonrandomized studies in meta-analyses. Eur J Epidemiol 25:603-605 DOI 10.1007/s10654-010-9491-z.

Stravodimos KG, Koritsiadis G, Lazaris AC, Agrogiannis G, Koutalellis G, Constantinides C, Patsouris E, Kapetanakis T, and Zervas A. 2009. Hydronephrosis promotes expression of hypoxia-inducible factor 1 alpha. Urol Int 82:38-42 DOI 10.1159/000176023.

Wu Y, Dong Q, Liu L, Han P, and Wei Q. 2014. The impact of tumor location and multifocality on prognosis for patients with upper tract urothelial carcinoma: a meta-analysis. Sci Rep 4:6361 DOI 10.1038/srep06361.

Xing Y, Xiong G, Fang D, Yang X, Li X, and Zhou L. 2016. Prognostic Value of Gene Methylation and Clinical Factors in Non-Muscle-Invasive Upper Tract Urothelial Carcinoma After Radical Nephroureterectomy. 
Clin Genitourin Cancer DOI 10.1016/j.clgc.2016.02.009.

\section{Yeh HC, Jan HC, Wu WJ, Li CC, Li WM, Ke HL, Huang SP, Liu CC, Lee YC, Yang SF, Liang PI, and} Huang CN. 2015. Concurrent Preoperative Presence of Hydronephrosis and Flank Pain Independently Predicts Worse Outcome of Upper Tract Urothelial Carcinoma. PLoS One 10:e0139624 DOI 10.1371/journal.pone.0139624.

Zhang B, Song Y, Jin J, Zhou LQ, He ZS, Shen C, He Q, Li J, Liu LB, Wang C, Chen XY, Fan Y, Hu S, Zhang L, Yu W, and Han WK. 2016. Preoperative Plasma Fibrinogen Level Represents an Independent Prognostic Factor in a Chinese Cohort of Patients with Upper Tract Urothelial Carcinoma. PLoS One 11:e0150193 DOI 10.1371/journal.pone.0150193.

Zhang X, Zhu Z, Zhong S, Xu T, and Shen Z. 2013. Ureteral tumours showing a worse prognosis than renal pelvis tumours may be attributed to ureteral tumours more likely to have hydronephrosis and less likely to have haematuria. World J Urol 31:155-160 DOI 10.1007/s00345-012-0885-2.

Zhang Z, Fang D, Chen X, Li X, Xiong G, Zhang L, He Q, and Zhou L. 2015. Predictive role of preoperative hydronephrosis on poor pathological outcomes and prognosis in upper tract urothelial carcinoma patients: Experience from a nationwide high-volume center in China. Oncol Lett 10:3113-3122 DOI 10.3892/ol.2015.3653.

Zintzaras E, and Ioannidis JP. 2005. HEGESMA: genome search meta-analysis and heterogeneity testing. Bioinformatics 21:3672-3673 DOI 10.1093/bioinformatics/bti536.

Zou L, Zhang L, Zhang H, Jiang H, and Ding Q. 2014. Comparison of post-operative intravesical recurrence and oncological outcomes after open versus laparoscopic nephroureterectomy for upper urinary tract urothelial carcinoma. World J Urol 32:565-570 DOI 10.1007/s00345-013-1160-x. 
1

Figure 1

Flow chart showing the study selection process.

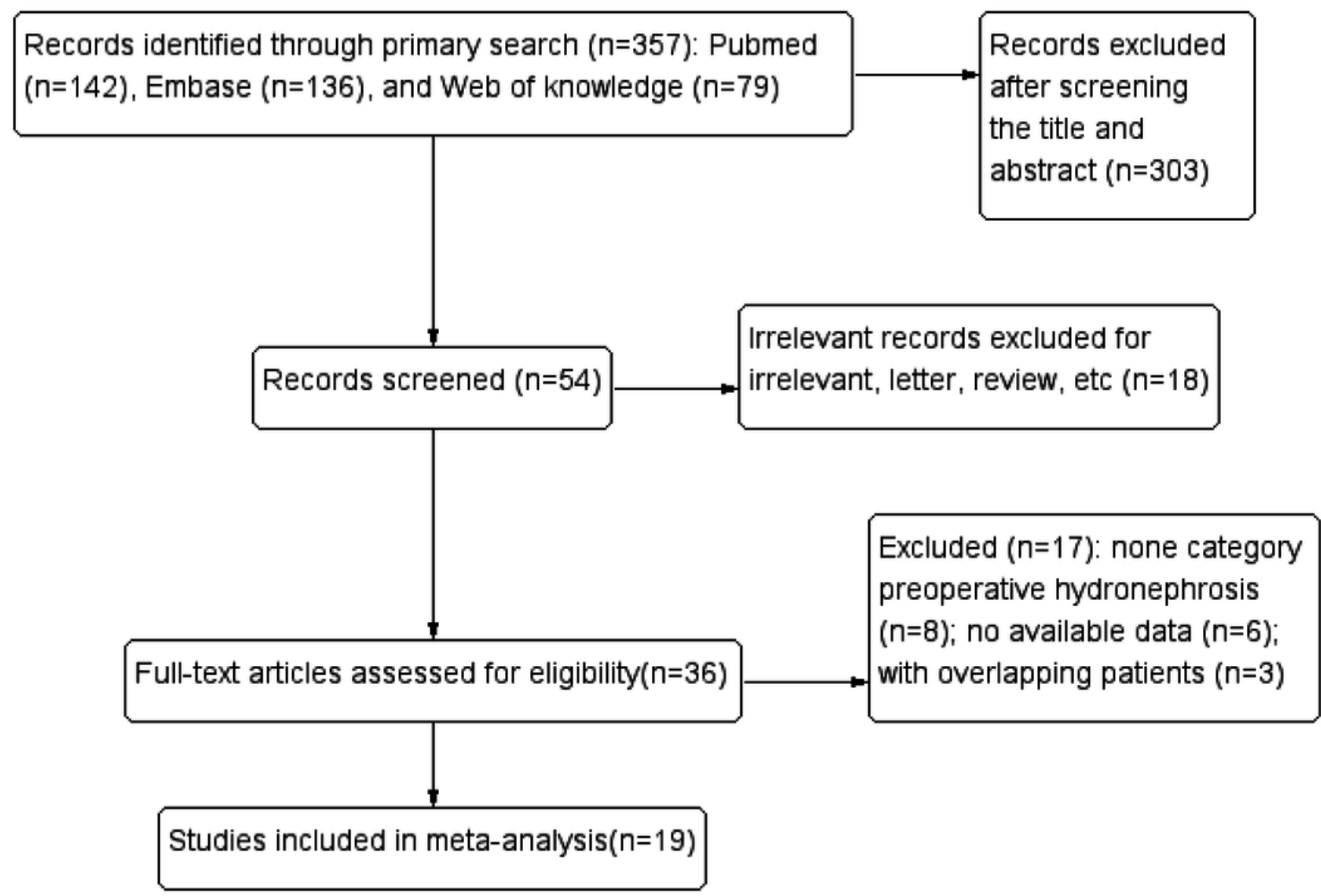


Figure $2 \mathrm{~A}$ and $2 \mathrm{~B}$

\section{(A) The hazard ratio (HR) of preoperative hydronephrosis associated with CSS in UTUC}

patients; (B) The hazard ratio (HR) of preoperative hydronephrosis associated with OS in

UTUC patients.

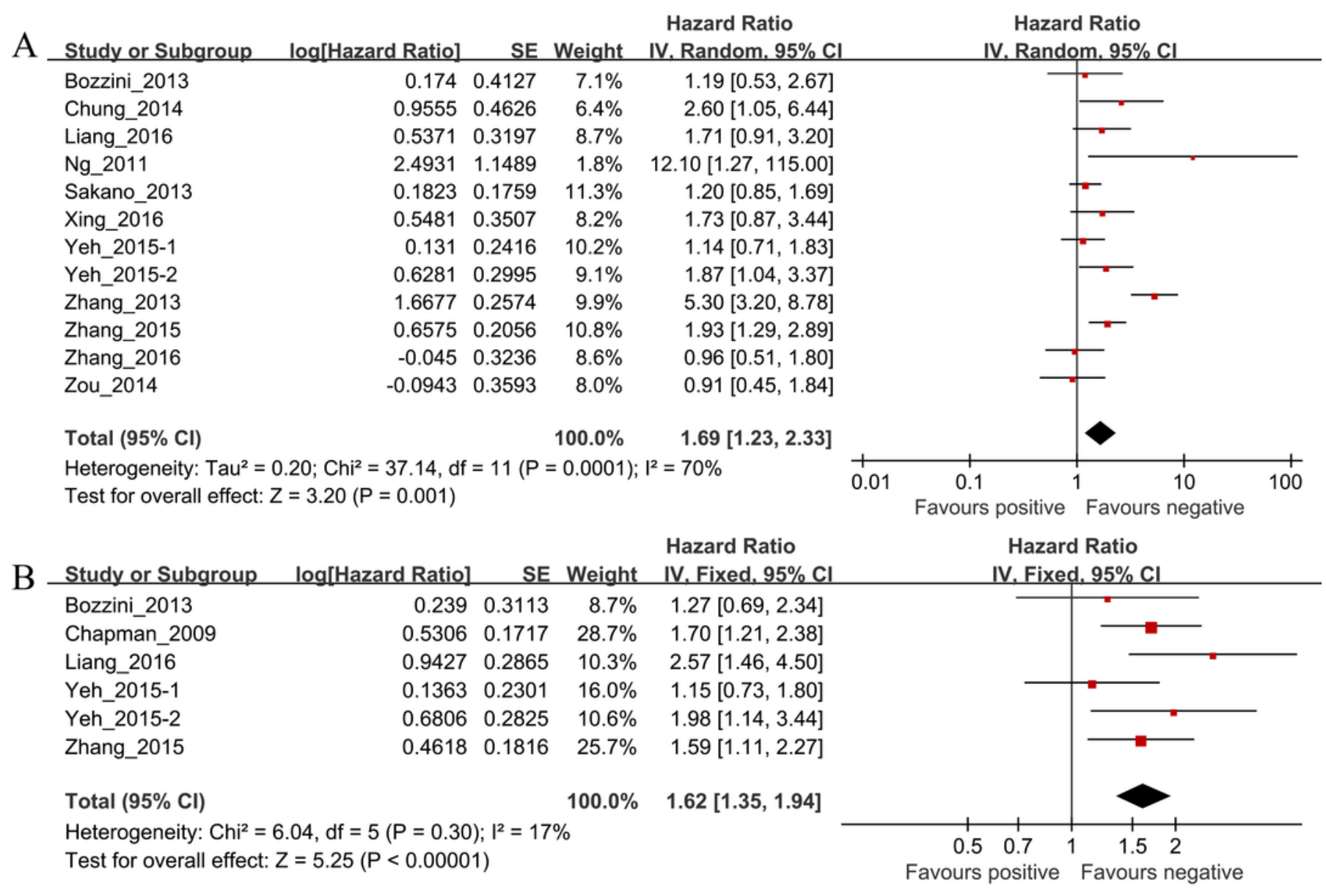


3

Figure $3 \mathrm{~A}$ and $3 \mathrm{~B}$

Funnel plots were used to evaluate publication bias on CSS. Begg's test and Egger's test were not significant intending no significant bias was observed on CSS (A and B). 
A

Begg's funnel plot with pseudo 95\% confidence limits

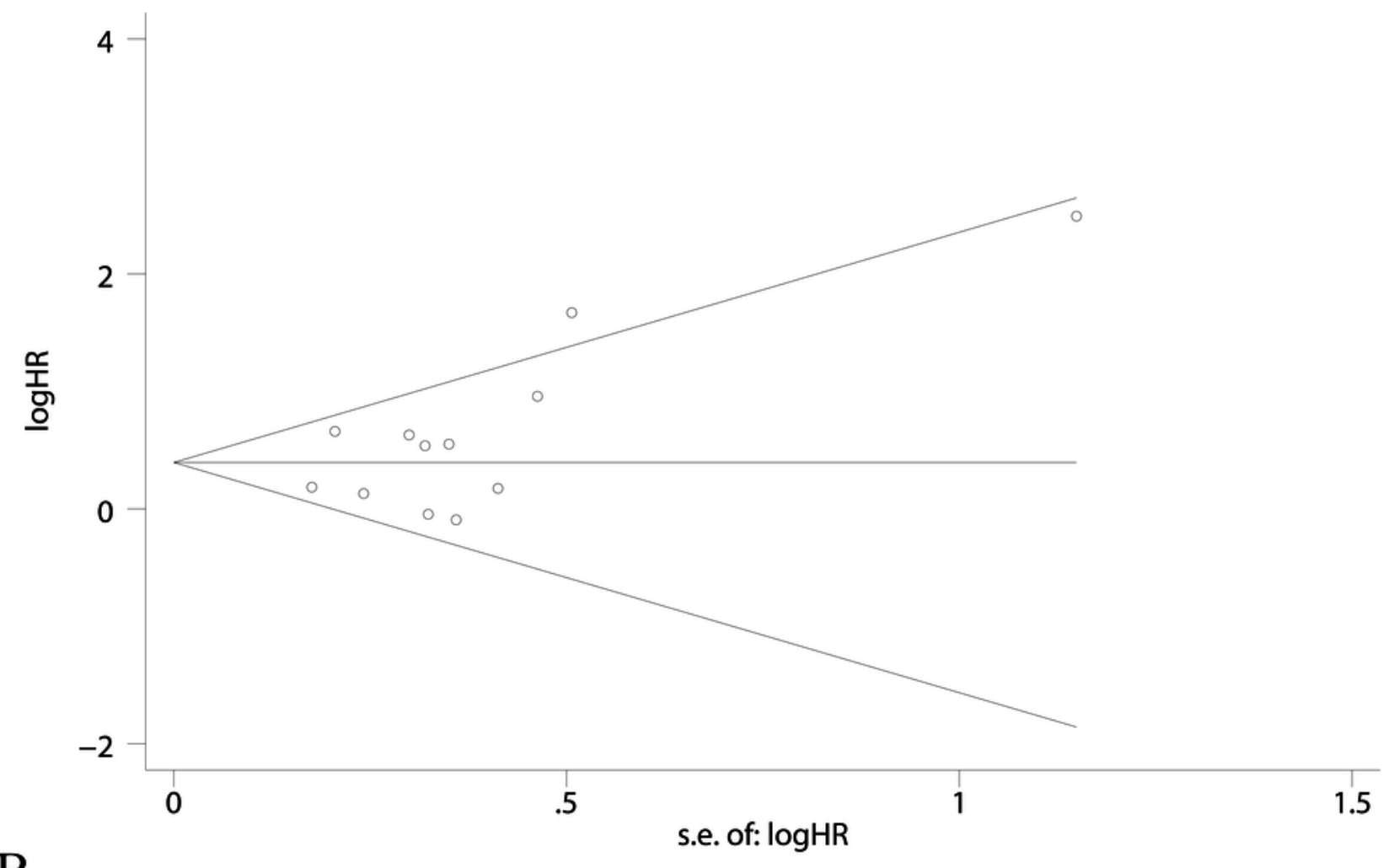

B

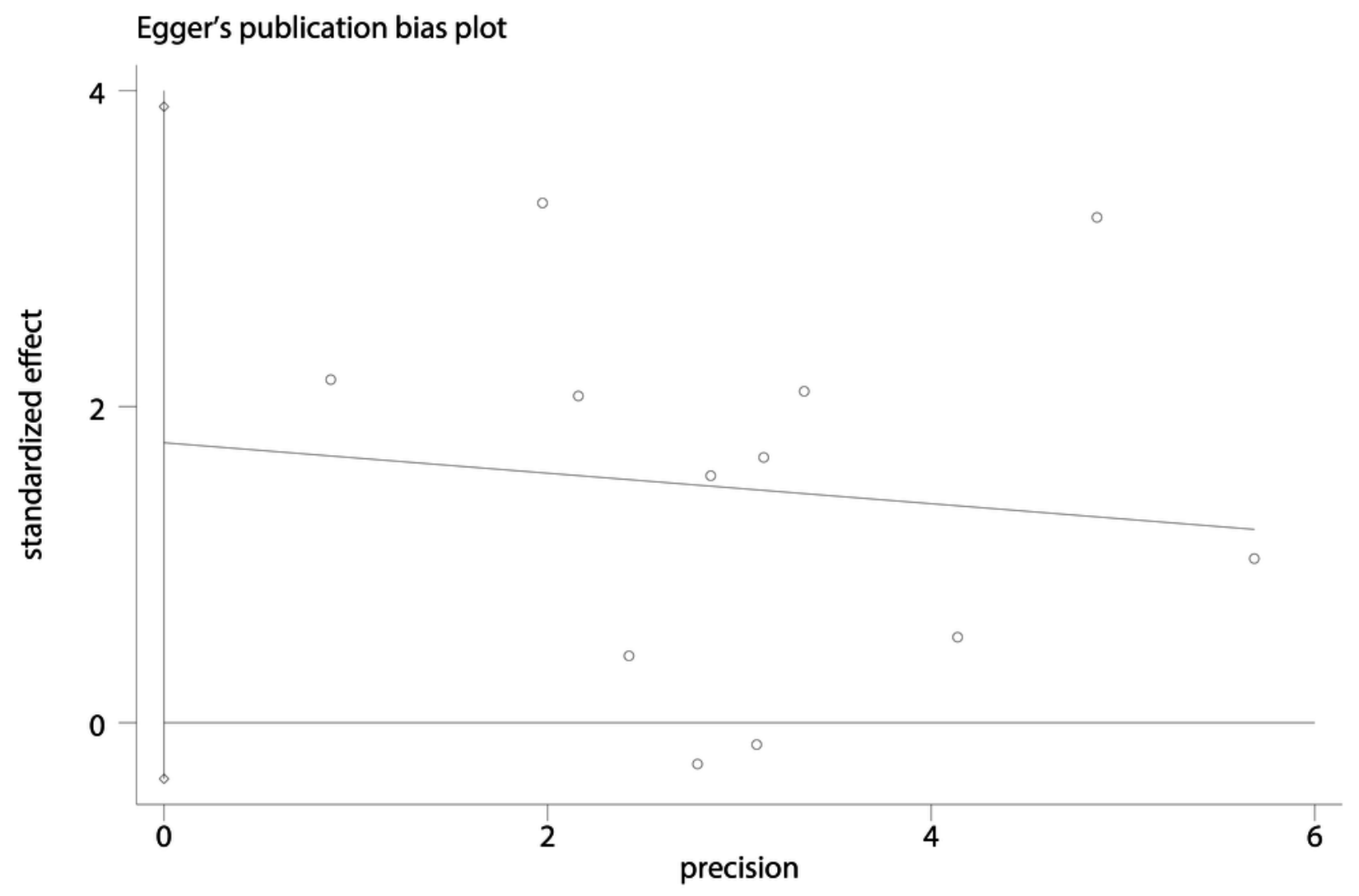




\section{Table 1 (on next page)}

Table 1

Summary of the characteristics of enrolled studies. 


\section{Table 1. Characteristics of the studies included.}

\begin{tabular}{|c|c|c|c|c|c|c|c|c|}
\hline Study & $\begin{array}{l}\text { Countr } \\
\mathrm{y}\end{array}$ & $\begin{array}{l}\text { Patie } \\
\text { nts }\end{array}$ & $\begin{array}{l}\text { Study } \\
\text { period }\end{array}$ & Age (range), yr & $\begin{array}{l}\text { Gender } \\
(\mathrm{m} / \mathrm{f})\end{array}$ & Cut off (Present/High grade) & FU (range), mon & $\begin{array}{l}\text { NOS } \\
\text { Score }\end{array}$ \\
\hline Cho_2007 & Korea & 104 & 1986- 2004 & $\mathrm{Md}=65(25-91)$ & $66 / 38$ & Grade $0 / 1 / 2$ vs. $3 / 4$ on CT, EU, US & $\mathrm{Md}=44(6-214)$ & 7 \\
\hline $\begin{array}{l}\text { Chapman_2 } \\
009\end{array}$ & USA & 308 & 1996- 2006 & $\begin{array}{l}\mathrm{Mn}=66.4(29.7- \\
90.4)\end{array}$ & $236 / 72$ & $\begin{array}{l}\text { Absence vs. presence on CT, US, } \\
\text { MRI, IVU }\end{array}$ & NA & 8 \\
\hline $\mathrm{Ng} \_2011$ & USA & 106 & 1993-2005 & $\mathrm{Md}=69(36-90)$ & $67 / 39$ & Absence vs. presence on $\mathrm{CT}$ & $\mathrm{Md}=47(1-164)$ & 8 \\
\hline $\begin{array}{l}\text { Messer_20 } \\
13\end{array}$ & USA & 408 & $1997-2008$ & $\begin{array}{l}\mathrm{Md}=69.1(\mathrm{IQR}, \\
15.5)\end{array}$ & $\begin{array}{l}254 / 15 \\
4\end{array}$ & $\begin{array}{l}\text { Mild/moderate vs. severe on CT, } \\
\text { MRI, IVP, US }\end{array}$ & NA & 7 \\
\hline $\begin{array}{l}\text { Bozzini_20 } \\
13\end{array}$ & France & 401 & $1995-2010$ & $\begin{array}{l}\mathrm{Md}=69.0(\mathrm{IQR} \\
60.0-76.0)\end{array}$ & $\begin{array}{l}249 / 15 \\
2\end{array}$ & $\begin{array}{l}\text { Absence vs. presence on CT, MRI, } \\
\text { IVU }\end{array}$ & $\begin{array}{l}\mathrm{Md}=26(\mathrm{IQR}, \\
9.0-49.0)\end{array}$ & 8 \\
\hline $\begin{array}{l}\text { Zhang_201 } \\
3\end{array}$ & China & 217 & $2000-2010$ & $\mathrm{Md}=69(62-81)$ & $130 / 87$ & $\begin{array}{l}\text { Absence vs. presence on CT, MRI, } \\
\text { IVP, US }\end{array}$ & $\mathrm{Md}=52$ & 8 \\
\hline $\begin{array}{l}\text { Hwang_20 } \\
13\end{array}$ & Korea & 114 & 2004-2010 & $\mathrm{Md}=71(41-84)$ & $88 / 26$ & $\begin{array}{l}\text { None/mild vs. moderate/severe on } \\
\text { CT, EU, US }\end{array}$ & $\begin{array}{l}\mathrm{Md}=26.5 \\
(23.5-31)\end{array}$ & 8 \\
\hline Luo_2013 & Taiwan & 162 & 2005-2010 & $\mathrm{Mn}=67.97$ & $81 / 81$ & $\begin{array}{l}\text { Grade } 0 / 1 / 2 \text { vs. } 3 / 4 \text { on urology } \\
\text { radiologists }\end{array}$ & $\mathrm{Md}=36.87$ & 8 \\
\hline $\begin{array}{l}\text { Sakano_20 } \\
13\end{array}$ & Japan & 536 & 1995- 2009 & $\mathrm{Md}=71(32-93)$ & $\begin{array}{l}370 / 16 \\
6\end{array}$ & Absence vs. presence & $\begin{array}{l}\text { Md }=40.9(3- \\
200)\end{array}$ & 7 \\
\hline Chen_2013 & China & 729 & 2002-2010 & $\mathrm{Mn}=66.5(20-94)$ & $\begin{array}{l}318 / 41 \\
1\end{array}$ & $\begin{array}{l}\text { Absence vs. presence on CT, MRI, } \\
\text { IVU }\end{array}$ & NA & 7 \\
\hline Zou_2014 & China & 122 & $1999-2013$ & $\mathrm{Md}=64(35-80)$ & $87 / 35$ & Absence vs. presence & $\mathrm{Md}=53(3-159)$ & 8 \\
\hline Colin_2014 & France & 151 & 1995-2010 & $\begin{array}{l}\mathrm{Md}=72.5(\mathrm{IQR} \\
63.4-78.1)\end{array}$ & $98 / 53$ & Absence vs. presence & $\begin{array}{l}\mathrm{Md}=18.5(\mathrm{IQR}, \\
9.5-37.9)\end{array}$ & 6 \\
\hline $\begin{array}{r}\text { Fradet } \\
2014\end{array}$ & Canada & 743 & $1990-2010$ & $\mathrm{Mn}=69.7$ & $\begin{array}{l}438 / 30 \\
4\end{array}$ & Absence vs. presence & $\begin{array}{l}\mathrm{Md}=24.8(\mathrm{IQR}, \\
7.69-56.76)\end{array}$ & 6 \\
\hline $\begin{array}{l}\text { Chung_201 } \\
4\end{array}$ & USA & 141 & 1998-2013 & $\mathrm{Md}=70(35-92)$ & $91 / 50$ & $\begin{array}{l}\text { None/mild vs. moderate/severe on } \\
\text { CT, IVP, US }\end{array}$ & $\mathrm{Md}=34(1-149)$ & 8 \\
\hline Yeh_2015 & Taiwan & 472 & 1991- 2013. & $\mathrm{Md}=67(24-95)$ & $\begin{array}{l}204 / 26 \\
8\end{array}$ & Absence vs. presence on $\mathrm{CT}$ & $\mathrm{Md}=33(1-233)$ & 7 \\
\hline $\begin{array}{l}\text { Zhang_201 } \\
5\end{array}$ & China & 520 & $2000-2010$ & NA & $\begin{array}{l}229 / 29 \\
1\end{array}$ & Absence vs. presence on CT, MRI & $\begin{array}{l}\mathrm{Md}=54(12- \\
151)\end{array}$ & 8 \\
\hline Liang_2016 & China & 172 & 2001-2014 & $\begin{array}{l}\mathrm{Md}=70(\mathrm{IQR}, 63- \\
77)\end{array}$ & $105 / 67$ & $\begin{array}{l}\text { None/mild vs. severe on CT, MRI, } \\
\text { US }\end{array}$ & $\begin{array}{l}\mathrm{Md}=44(\mathrm{IQR}, \\
24-62)\end{array}$ & 7 \\
\hline Xing_2016 & China & 192 & $2000-2013$ & NA & $114 / 78$ & Absence vs. presence on CT, US & $\mathrm{Md}=65(3-144)$ & 8 \\
\hline $\begin{array}{l}\text { Zhang_201 } \\
6\end{array}$ & China & 184 & 2006-2008 & $\mathrm{Md}=70(61-75)$ & $84 / 100$ & $\begin{array}{l}\text { Absence vs. presence on CT, MRI, } \\
\text { US }\end{array}$ & $\mathrm{Md}=78(34-92)$ & 8 \\
\hline
\end{tabular}

\section{Notes.}

3 Abbreviations: $\mathrm{CT}=$ computed tomography; $\mathrm{EU}=$ excretory urography; $\mathrm{FU}=$ follow-up; IQR = interquartile range; IVP = intravenous pyelogram;

$4 \mathrm{IVU}=$ intravenous urograms; $\mathrm{Md}=$ median; $\mathrm{Mn}=$ mean; $\mathrm{MRI}=$ magnetic resonance imaging; $\mathrm{NA}=$ not available; $\mathrm{US}=\mathrm{ultrasound}$; mon = month; $5 \mathrm{yr}=$ year. 


\section{Table 2 (on next page)}

Table 2

HR values of CSS, OS, RFS and MFS of UTUC. 
1 Table 2. HR values of the CSS, OS, RFS and MFS of the UTUC subgroups.

\begin{tabular}{llllllll}
\hline Outcome & Studies (n) & Patients & HR & $\mathbf{9 5 \% C I}$ & P value & Model & Heterogeneity \\
\cline { 6 - 8 } & & & & & & & $\mathbf{I}^{2}$, P value \\
\hline CSS & 12 & 3063 & 1.69 & $1.23-2.33$ & 0.001 & Random & $70 \%, 0.001$ \\
OS & 6 & 1873 & 1.62 & $1.35-1.94$ & 0.000 & Fixed & $17 \%, 0.30$ \\
RFS & 7 & 695 & 1.95 & $1.26-3.04$ & 0.003 & Random & $54 \%, 0.04$ \\
MFS & 4 & 820 & 1.55 & $1.04-2.33$ & 0.03 & Fixed & $27 \%, 0.25$ \\
\hline
\end{tabular}

2 Notes.

3 Abbreviations: $\mathrm{CI}=$ confidence interval; $\mathrm{CSS}$ = cancer-specific survival; Fixed = fixed, inverse variance model;

$4 \quad \mathrm{HR}=$ hazard ratio; $\mathrm{I}^{2}=\mathrm{I}$-squared; MFS: metastasis-free survival; OS = overall survival; Random = random, I-V

5 heterogeneity model; RFS = recurrence-free survival.

6 


\section{Table 3 (on next page)}

Table 3

OR values for UTUC subgroups according to clinical characteristics. 
1 Table 3. OR values for the UTUC subgroups according to clinical characteristics.

\begin{tabular}{llllllll}
\hline Outcome of interest & $\begin{array}{l}\text { Stu } \\
\text { dies }\end{array}$ & $\begin{array}{l}\text { Patie } \\
\text { nts }\end{array}$ & OR & $\mathbf{9 5 \% C I}$ & P value & Model & Heterogeneity \\
\cline { 3 - 8 } & 9 & 2462 & 3.12 & $1.85-5.27$ & 0.000 & Random & $86 \%, 0.000$ \\
\hline Ta/1 vs. T2-4 & 3 & 799 & 1.66 & $1.20-2.29$ & 0.002 & Fixed & $32 \%, 0.23$ \\
High grade vs. Low grade & 2 & 921 & 1.42 & $0.75-2.69$ & 0.28 & Random & $76 \%, 0.04$ \\
G3 vs. G1+G2 & 2 & 921 & 0.94 & $0.49-1.79$ & 0.85 & Fixed & $0 \%, 0.42$ \\
G2+G3 vs. G1 & 6 & 1834 & 1.60 & $1.13-2.26$ & 0.009 & Fixed & $0 \%, 0.55$ \\
Lymph node metastasis vs. No & & & & & & & \\
lymph node metastasis & 10 & 2858 & 4.28 & $2.91-6.30$ & 0.000 & Random & $78 \%, 0.000$ \\
Renal pelvis vs. Ureter & 2 & 737 & 1.28 & $0.92-1.77$ & 0.14 & Fixed & $0 \%, 0.68$ \\
Recurrence vs. No recurrence & 7 & 2556 & 1.01 & $0.86-1.19$ & 0.90 & Fixed & $6 \%, 0.38$ \\
Gender (Male vs. Female) & & & & & & &
\end{tabular}

2 Notes.

3 Abbreviations: $\mathrm{CI}=$ confidence interval; Fixed $=$ fixed, inverse variance model; $\mathrm{I}^{2}=\mathrm{I}$-squared; $\mathrm{OR}=$ odds ratio;

$4 \quad$ Random $=$ random, I-V heterogeneity model.

5 